\title{
CESPUC
}

\section{A TRADUÇÃO DO HUMOR NAS LEGENDAS DE THE OFFICE}

\author{
Nathalia Cristina de Freitas Campos*
}

\begin{abstract}
Resumo
Este artigo analisa como é feita a tradução do humor por meio das legendas em português da série The Office e como a revisão pode ajudar para que a legenda capte o máximo possível do contexto de cada cena. Foram feitas análises sobre caracterizações de tradução, humor e revisão, apenas para esboçar o assunto rapidamente e introduzir como o humor é abordado em The Office e mais especificamente, como ele é abordado através das legendas dos DVDs brasileiros da série. Por fim, foi feita uma análise de cenas específicas, observando se as legendas conseguem ou não transmitir sua mensagem para o telespectador em um curto espaço de tempo e sugestões de maneiras que possam melhorar, para mostrar como a revisão pode ajudar nesse aspecto específico, de modo a manter a fidelidade de significado entre a tradução e o diálogo original.
\end{abstract}

Palavras-chave: Legendagem. Revisão. Humor. Séries de TV. The Office.

\section{THE TRANSLATION OF HUMOR IN THE SUBTITLES OF THE OFFICE}

Recebido em 27/04/2017

Aceito em 07/07/2017

This article aims to analyze how the translation of humor was done through the Portuguese subtitles of the series The Office and how proofreading can help in a way that makes the subtitles capture the maximum amount of context possible in each scene. Characterizations about the nature of translation, humor and proofreading were analyzed, just to quickly outline the subject and introduce how humor is approached in The Office and, more specifically, how it is approached through the subtitles of the Brazilian DVDs of the series. Finally, an analysis of specific scene was made, observing if the subtitles manage or not to convey their message to the viewer in a short amount of time and suggestions of ways to improve it, to show how proofreading can help in this particular aspect, so as to maintain the meaning between a translation and the original dialogue as faithful as possible.

Keywords: Subtitling. Proofreading. Humour. TV series. The Office.

* Especialista em Revisão de Textos pelo Instituto de Educação Continuada / IEC PUC Minas. O presente artigo traz os resultados de pesquisa que consistiu em Trabalho de Conclusão do Curso, requisito para a obtenção do título de Especialista em Revisão de Textos, orientado pela Prof. ${ }^{a}$ Dr. ${ }^{a}$ Priscila Campolina de Sá Campello. 


\section{（ESPUC \\ 20 SEMESTRE DE $2017-$ N. 31}

\section{Introdução}

A tradução é um assunto muito complexo, que apresenta variados desdobramentos e estudos. No presente artigo, fez-se a escolha pela discussão de como o humor se traduz nas legendas de uma série de TV, The Office, e qual é o papel da revisão para que a mensagem seja repassada para o telespectador com o máximo de equivalência possível do inglês com o português.

A primeira parte deste artigo apresenta uma caracterização da tradução, como ela é importante num aspecto geral e como ela pode ser melhorada. O segundo ponto aborda quais são os desafios da revisão de uma tradução, analisando especificamente o caso de produtos audiovisuais e legendas. Em seguida, trata-se de como é feita a caracterização do que seja humor, um ponto importante para entender melhor e classificar piadas, para que, na quarta seção, fossem analisados os aspectos conjuntos de tradução, humor e legendas. O objeto de estudo deste artigo é fruto de interesse pessoal sobre o assunto de legendas que tenham a ver com humor, devido a constatações feitas, ao longo dos anos, quanto à falta de sentido em variados produtos midiáticos. O quinto ponto a ser observado, portanto, é de que modo as teorias do humor se encaixam na série The Office, e já que a intenção da série é ser humorística, na última parte realizou-se uma análise de cenas para ver se e como ele foi transmitido nas legendas da série, evidenciando como uma revisão poderia ajudar na obtenção desse objetivo.

\section{A caracterização da tradução}

Existem diversas definições sobre a tradução e quais são suas dificuldades e esse é realmente um tema extenso, complicado, que está em constante evolução. Um tópico em que quase todos os estudiosos do assunto concordam, entretanto, é que a tradução é uma atividade essencial, que deve levar em consideração não só o texto original e seu contexto, mas também o texto traduzido e o seu destino. Os estudiosos também têm clareza quanto ao fato de que nem sempre um texto vai poder ser traduzido de modo que o significado original continue sendo o mesmo, mas talvez por isso, a tradução seja um objeto de estudo tão amplo e com tantas ramificações:

Tradução é um ponto de contato entre as pessoas e já que é raro que duas pessoas tenham o mesmo acesso ao poder, o tradutor está numa posição privilegiada de mediador, de fazer explícitas as diferenças entre as culturas, expor as injustiças ou contribuir com a diversidade no mundo. (GILL; GUZMÁN apud BAKER, 2011, p. 15. Tradução minha) ${ }^{1}$.

Baker (2011), por exemplo, aborda em seu livro In Other Words: A Coursebook on Translation, como a tradução adequada depende de fatores como o texto fonte, a forma em que ele foi escrito e o modo como o tradutor escolheu traduzir esse texto. Para a autora, é importante levar em consideração, nesses casos, fatores como as expectativas, conhecimentos

1 Translation is a point of contact between peoples, and since it is rare that two peoples have the same access to power, the translator is in a privileged position as mediator, to make explicit the differences between cultures, expose injustices or contribute to diversity in the world. 


\section{（ESPUC \\ 20 SEMESTRE DE $2017-$ N. 31}

prévios e mesmo preconceitos dos leitores (nesse caso, telespectadores), além da noção que o tradutor tem de seu trabalho, do que é apropriado para determinadas situações ou não e também as restrições (como censura) e intervenções que podem ocorrer nesse mesmo trabalho.

Em seu artigo "Humor and Translation - an Interdiscipline", Patrick Zabalbeascoa (2005) aborda algumas dificuldades para entender a tradução. Segundo ele, enquanto os linguistas estão interessados nos padrões de semelhanças e diferenças entre as línguas (como gramática), os tradutores têm que se preocupar com itens mais textuais (como enunciados). Muitas vezes, portanto, as traduções contrariam a norma padrão ou acabam resultando em palavras e frases que não são comuns na língua alvo da tradução. Ele ressalta que variadas tentativas de entender a tradução como uma espécie de verdade absoluta e única acabaram falhando. Para ele, existem tantas variáveis diferentes que afetam a tradução que é perfeitamente possível que os estudiosos ainda não tenham identificado todas elas. E continua, apontando as mais óbvias, em dez pontos:

a) a(s) língua(s)/cultura(s) da qual se vai traduzir (incluindo todos os aspectos de variáveis da língua, como dialetos e registros);

(b) a(s) língua(s)/cultura(s) para a qual se está traduzindo, com o(s) propósito(s) e justificativa(s) para a existência da versão traduzida;

(d) a natureza do texto, incluindo parâmetros como textualidade, gênero, estilo e discurso;

(e) o(s) destinatário(s) pretendido(s), como se assume que ele(s) são;

(f) o(s) cliente(s) ou iniciador(es) da tradução, quais são suas necessidades e demandas;

(g) a(s) expectativa(s) para o texto traduzido e preconceito contra traduções e tradutores;

(h) o(s) tradutor(es): humano (individual ou times), completamente automático, ou assistido por computador;

(i) as condições em que a tarefa é feita (prazos, materiais, motivação, etc.);

(j) o meio, o modo e os meios de comunicação: oral, escrita, audiovisual, privada, mídia de massas, etc. (ZABALBEASCOA, 2005, p. 186. Tradução minha.)2

Zabalbeascoa enfatiza que, com tantas variáveis (mesmo que nem todas elas se apliquem a todos os textos), é extremamente necessário seguir alguns procedimentos que beneficiem e ajudem o tradutor e também o estudioso de tradução. Ele define dois: um chamado de "mapeamento", que consiste em localizar e analisar itens textuais de acordo com classificações relevantes e o outro que ele define como "priorização", que seria estabelecer o que é mais importante para cada caso, quando estamos falando sobre tradução e como analisar a importância de cada item e de cada aspecto. Com essas definições prontas, é possível criterizar um molde para que a tradução seja feita da maneira mais próxima ao original possível.

2 (a) the language $(\mathrm{s}) /$ culture(s) one is translating from (including all aspects of language variation, such as dialects and registers) (b) the language(s)/culture(s) one is translating into (c) the purpose(s) and justification(s) for the existence of the translated version (d) the nature of the text, including parameters such as textuality, genre, style and discourse (e) the intended recipient(s), what they are assumed to be like (f) the client(s) or translation initiator(s), their needs and demands (g) the expectation(s) for the translated text and prejudice towards translations and translators (h) the translator(s): human (individuals or teams), fully automatic, or computer assisted (i) the conditions in which the task is carried out (deadline, materials, motivation, etc.) (j) the medium, mode and means of communication: oral, written, audiovisual, private, mass media, etc. 


\section{Tradução e revisão}

Em seu artigo "A intervenção textual como atividade discursiva", Muniz Junior (2009) fala sobre o papel da intervenção textual, lembrando que é uma atividade que significa, de maneira simplificada, preparar um texto para sua circulação pública. Ele lembra que o profissional analisa leituras prováveis do texto e propõe reformulações textuais "para que o texto tenha uma recepção o mais próximo possível da esperada ou desejada.” (MUNIZ JUNIOR, 2009, p.7). Quando estamos analisando legendas de séries de TV, é muito importante levar esse fator em consideração, já que mostra a importância que um trabalho de revisão pode ter para a melhoria da qualidade do produto.

Na tese de doutoramento $\mathrm{A}$ tradução para legendas: dos polissistemas à singularidade do tradutor, Carolina Carvalho (2005) faz um traçado do caminho percorrido pela tradução de produtos audiovisuais no Brasil, baseando-se em experiências próprias como tradutora profissional. De acordo com ela, depois da negociação com uma distribuidora multinacional, agências que comercializam / exibem esse material definem uma ou mais modalidades diferentes de tradução. A agência negocia com uma produtora como vai funcionar a pós-produção, sendo responsável por contratar o serviço de tradução, ou passando essa responsabilidade para a produtora em questão. O tradutor recebe esse material com as informações necessárias para que possa realizar seu serviço de maneira eficiente e depois de pronta, a tradução retorna à produtora.

Ela afirma que a revisão ou controle de qualidade também é feito, "o que pode ocorrer na produtora, no laboratório ou mesmo na distribuidora que encomendou o serviço." (CARVALHO, 2005 , p. 85). Depois disso, o produto fica disponível para o cliente e sujeito a críticas. Esse é um aspecto importante, porque, mesmo que o produto possa ser alvo de críticas, dificilmente ele será devolvido para a distribuidora ou vai parar de ser vendido por causa de problemas na tradução. Carvalho (2005) explica que é necessário que o tradutor esteja sintonizado com o básico do sistema de funcionamento do meio para o qual está traduzindo:

[...] pode-se notar que o tradutor inserido no polissistema de tradução audiovisual não deve apenas dominar seu — nada trivial — ofício de tradução de textos, mas também conhecer o funcionamento básico da produção de materiais audiovisuais. (CARVALHO, 2005, p. 85).

Clarissa dos Santos (2007) explana ainda melhor esse conceito, mas analisando o ponto de vista do revisor. Em sua tese de doutoramento A revisão como atividade interventora no processo tradutório, ela explica que, na grande maioria das vezes, a revisão não é vista com a mesma seriedade que outras etapas do processo de editoração de um texto e os revisores acabam até sendo menos reconhecidos e ganhando menos. Ela menciona ainda que, em casos mais extremos, os revisores foram excluídos do processo, que agora é feito totalmente por computadores. Ao falar da revisão de tradução, ela afirma que é comum ouvir que o revisor é um tradutor frustrado, que não tem o talento necessário para a tradução e foca na revisão, porque é uma atividade com menos demanda de capacidade: 


\section{CESPUC}

[...] também neste mercado, o revisor é visto como um profissional inferior e menos competente do que o tradutor; alguém que deve manter a imparcialidade e a invisibilidade de seu trabalho enquanto o tradutor ocupa um posto visível e quase co-autoral na construção do significado. Também no mercado tradutório é o revisor um profissional mais mal remunerado e menos reconhecido do que o tradutor. (SANTOS, 2007, p. 109).

Santos (2007) explica, portanto, que é necessário mudar o olhar sobre as atividades do revisor, já que ele é um profissional que participa ativamente da construção de sentido do texto. Ela afirma que é importante esse tipo de olhar, o que analisa a revisão como uma atividade interventora, que também é responsável pela produção de sentidos, porque obriga a repensar a posição do revisor e seu relacionamento com os outros profissionais desse processo.

Para a revisão da tradução, Santos (2007) conclui que o ideal seria que o revisor fosse também um tradutor, que conhecesse bem as demandas do processo de tradução e, melhor ainda, que fosse um tradutor mais experiente do que os tradutores cujos ele vai revisar. trabalhos. Ela afirma que isso já acontece em algumas empresas, com um tradutor mais experiente no cargo de tradutor-revisor, o que ajudar a otimizar tanto o processo de tradução quanto o processo de revisão.

Voltando aos aspectos básicos da revisão, além de ser importante que o tradutor conheça o produto com o qual está trabalhando, é extremamente necessário que o revisor também esteja minimamente familiarizado com o contexto do que está revisando. Em muitos casos, o profissional que vai traduzir e que vai revisar é o mesmo. Um conhecimento prévio é necessário para que ele possa captar da melhor maneira as nuances do trabalho que são necessárias para o bom entendimento. Abaixo, nas análises das cenas de The Office, é possível perceber como acabou faltando, no processo de tradução e revisão, um olhar que entendesse melhor a mensagem da série.

\section{A caracterização do humor}

O humor, assim como a tradução, não tem uma definição específica, o que não impede diferentes estudiosos de tentarem defini-lo. Vandaele (2010), por exemplo, no artigo "Humor in Translation", afirma que humor é o que causa as risadas que são capturadas como respostas para a incerteza, a surpresa e os insights construídos pela nossa mente. "Humor é, portanto, sem dúvidas, algo distintamente humano: nossa mente simbólica pode transformar a incerteza, a surpresa e o perigo no que chamamos de humor." (VANDAELE, 2010, p. 148. Tradução minha). ${ }^{3}$ É uma observação muito bem colocada e que fica ainda mais interessante quando passamos a considerar os diferentes aspectos do que faz o outro rir e os contextos que estão inseridos na procura pelo que é engraçado para diferentes pessoas, de diferentes culturas.

Existem teses populares que afirmam que o humor é cultural e uma análise dos estudos de Sírio Possenti (2014), no livro Humor, Língua e Discurso, faz aflorar a percepção de que essa é uma afirmação verdadeira: o humor é, sim, cultural, mas apenas se considerarmos que

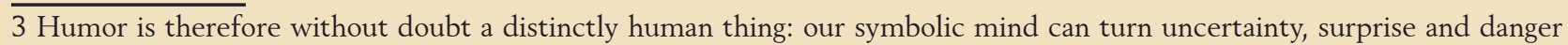
into what we call humor. 


\section{CESPUC}

é necessário conhecer a cultura local também para entender, por exemplo, histórias infantis e mitos da região. Essa é uma base importante quando consideramos uma série de TV, já que, se julgarmos o humor apenas como algo cultural, não faria sentido a legendagem de um produto dos Estados Unidos no Brasil, por exemplo.

Possenti (2014) cita estudos de Pagnol (1953) sobre a temática do humor cultural, mas observa que o autor só escreve sobre os temas do riso e se esquece de falar sobre as técnicas que produzem humor, que serão abordadas abaixo. Possenti lembra que "nenhum tema é, por si mesmo, criador de riso. Como já se tornou lugar-comum, o que faz rir deriva da técnica, não do conteúdo do texto humorístico." (POSSENTI, 2014, p.5). Essa é uma questão que interfere diretamente na discussão sobre a tradução e a revisão, especialmente no quesito "tradução de séries de TV", que está sendo abordado nesse trabalho, já que muitas piadas perdem o sentido se traduzidas literalmente por aqui, mas as mesmas podem continuar engraçadas se forem adaptadas de acordo com referenciais conhecidos por brasileiros. Dito isso, é importante analisar um outro aspecto do humor, além do contexto cultural: as técnicas para fazer o outro rir.

Vandaele (1999) propõe, em seu artigo "Each time we laugh: translated humour in screen comedy", uma estrutura que analisa as características da incongruência e da superioridade quando falamos sobre humor. Ele lembra que todas as categorias e subcategorias propostas devem ser interpretadas como fatores de humor, ao invés de elementos essenciais necessários para o humor.

Os tipos de incongruência são: 1) linguística; 2) pragmática; 3) narrativa; 4) intertextual; 5) social e 6) natural, enquanto os tipos de superioridade identificados por ele são: 1) superioridade negativa e 2) superioridade positiva, esta podendo ser dividida em outras três subcategorias: 2a) solução de problemas, 2b) institucionalização e 2c) circunstâncias gerais.

Vandaele (2010) menciona que muitas das teorias sociais do humor, geralmente baseadas em Thomas Hobbes e Henri Bergson, definem o humor analisando a superioridade, a hostilidade, a agressividade, a depreciação, o escárnio e, por causa disso, muitas vezes são chamadas de "teorias de superioridade." É uma categoria mais simples de definir, já que como o próprio Vandaele afirma, quem é "superior é sempre superior a um outro alguém." (VANDAELE, 1999, p. 241. Tradução minha). ${ }^{4}$ Há, por parte desses estudiosos, uma insistência em que o humor constantemente faz uma vítima ou alvo se passar por ridículo e produz um senso de autoestima elevado em quem está apreciando essa piada:

\footnotetext{
Humor realmente favorece um tipo peculiar de socialização: explora, confirma ou cria inclusão (para os grupos de dentro), exclusão (para os grupos de fora) e hierarquias entre pessoas (entre quem compreende, quem não compreende, entre as pessoas 'normais' e 'nãonormais', etc.). (VANDAELE, 2010, p. 148. Tradução minha). ${ }^{5}$
}

4 "superior is always being superior-to-someone."

5 Humor indeed fosters a peculiar sort of socialization: it exploits, confirms or creates inclusion (or in-groups), exclusion (out-groups), and hierarchies between persons (between comprehenders and non-comprehenders, between "normal" and "abnormal" persons, etc.). 


\title{
CESPUC \\ 2O SEMESTRE DE $2017-$ N. 31
}

No caso das teorias de incongruência, Vandaele (2010) afirma que elas não estão tão interessadas nos aspectos sociais, mas nas características cognitivas do humor. A incongruência é definida por Chapman e Foot (1976 apud Vandaele, 1999, p. 239) como "um conflito entre o que é esperado e o que acontece de verdade na piada." ${ }^{6}$ Shultz (1997 apud Vandaele, 2010, p. 148) também lembra que o conceito de expectativa é incluído muitas vezes em definições de incongruência, já que, em termos cômicos, geralmente se desprezam as expectativas que são construídas por regras bem conhecidas cognitivamente. De forma generalizada, é possível dizer que a incongruência acontece quando as regras "não escritas", de boa etiqueta e socialização, normalmente seguidas pela sociedade, são violadas.

Outra observação importante feita por Vandaele (2010) sobre a teoria de incongruência é que existe uma lógica alternativa no caso do humor:

\begin{abstract}
Além da construção de expectativas e escárnio, existe uma "solução" para a situação inesperada ou mensagem. Isso significa que, apesar de sua incongruência observada, o humor também é congruente (compreensível) de uma maneira diferente. (VANDAELE, 2010, p. 148. Tradução minha). ${ }^{7}$
\end{abstract}

Um problema que isso pode apresentar, no caso da tradução, é que a capacidade de absorver informações é extremamente pessoal, então uma mesma piada vai ser recepcionada de maneiras diferentes por diferentes pessoas. Esse já é um grande desafio que o humor enfrenta sozinho, mas quando acrescentamos a tradução de piadas, isso se torna uma tarefa ainda mais complicada, já que é necessário transmitir a mensagem original de forma que a piada faça sentido, sem que o contexto geral da série, nesse caso, fique comprometido.

Patrick Zabalbeascoa (1996), no seu estudo Translating jokes for dubbed television situation comedies, propõe outra forma de analisar as piadas, utilizando-se do ponto de vista do tradutor. São elas: 1) internacional; 2) binacional; 3) com cultura e instituições nacionais; 4) com o senso de humor nacional; 5) que depende da língua; 6) visual e 7) complexa.

Existem variadas teorias de análise de humor, mas é possível notar que não existe um padrão para analisar piadas e tudo vai depender, na verdade, do ponto de vista de quem está vendo, estudando e do contexto de cada situação apresentada. Para analisar a série The Office, vamos utilizar as teorias da incongruência e da superioridade, mas especialmente o tópico de Zabalbeascoa (1996) sobre piadas que dependem da língua, porque é um recorte que mostra mais profundamente alguns problemas de legendagem e revisão que poderiam ser mais facilmente resolvidos.

\section{Tradução, humor e legendas}

Em seu artigo "Verbally Expressed Humour on Screen: Reflections on Translation and Reception", Chiaro (2006) faz uma análise da tradução de filmes de comédia do inglês para 6 "a conflict between what is expected and what actually occurs in the joke"

7 Besides a setting-up of expectations and a flouting, there is a "solution" to the unexpected situation or message. This means that, despite its perceived incongruity, the humor is also congruous (understandable) in a different way. 


\section{（ESPUC \\ 2O SEMESTRE DE $2017-$ N. 31}

o italiano e levanta questionamentos importantes sobre humor e tradução. Ela menciona as diferentes variáveis que acabam por tornar uma cena engraçada, como, por exemplo, o diálogo, letras de música, textos escritos como cartas, banners, jornais, mensagens de texto, sons de fundo, expressões faciais e movimentos dos atores, etc. e lembra que a intervenção de um tradutor só aparece refletindo um desses aspectos, enquanto os outros permanecem imutáveis.

As comédias, especialmente, tendem a se utilizar de mais de um desses elementos para que a piada seja engraçada, sendo assim, "se o código verbal é a única dimensão que pode ser manipulada para auxiliar a cultura alvo na percepção do humor, o trabalho do tradutor é delicado." (CHIARO, 2006, p. 198. Tradução minha). ${ }^{8}$

Outro fator importante discutido pela autora é que as legendas devem seguir certos padrões: não podem passar um espaço / limite de tempo já determinado. Em "The Sitcom Revisited: The Translation of Humor in a Polysemiotic Text", Chile (1999), por sua vez, lembra que, quando consideramos todos esses aspectos, é surpreendente que algumas legendas sejam consideradas, de fato, boas:

Legendagem é um tipo de tradução em que os princípios da Teoria da Relevância como discutida por Koviac (1994) são, até certo ponto, perfeitamente aplicáveis, já que se espera do tradutor que ele mantenha a essência da mensagem (a relevância dela), requerendo o mínimo esforço do leitor para processá-la. Com as limitações de espaço, tempo e leitura restringindo o uso da linguagem nas legendas, o tradutor deve escolher qual informação vai ser traduzida. (CHILE, 1999, p. 174. Tradução minha). ${ }^{9}$

Chiaro (2006) menciona a importância que os estudos de humor têm no campo de estudos de tradução, exatamente por ser um tema interdisciplinar. Para ela, questões que devem ser respondidas nesse caso são, por exemplo, o tanto que uma resposta positiva para a tradução de Humor Verbalmente Expressado $(\mathrm{VEH})^{10}$ depende de diferenças culturais, diferenças individuais ou da tradução sozinha. Ela afirma que:

Todos os humanos são capazes de produzir risadas e estudos transculturais até a presente data revelam a existência de variados denominadores transculturais comuns (RUCH, 1998). Esses resultados podem nos levar a acreditar que as diferenças linguísticas sozinhas são um obstáculo para uma resposta positiva do humor entre as culturas. (CHIARO, 2006, p. 207. Tradução minha). ${ }^{11}$

É necessário, por fim, lembrar sobre a efemeridade de uma legenda, já que muito provavelmente ela vai ser lida uma única vez, muito rapidamente e está inserida num conjunto em que figuram várias outras informações que estão acontecendo na tela no mesmo momento.

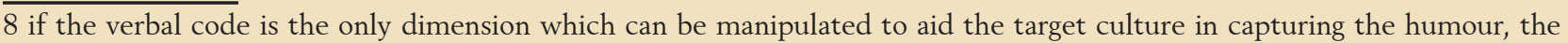
translator's job is a delicate one.

9 subtitling is a type of translation to which the principles of the Theory of Relevance as discussed by Kovacic (1994) are, to a certain extent, perfectly applicable, since the translator is expected to keep the essence of the message (the relevance of it), requiring the minimum effort from the reader to process it. As space, time and reading limitations constrain the use of language in the subtitles, the translator has to select what information should be translated.

10 Verbally Expressed Humor

11 All humans are capable of producing laughter, and cross-cultural studies to date reveal the existence of several transcultural common denominators (Ruch, 1998). These results could well lead us to believe that linguistic differences alone are an obstacle to a positive humour response across cultures. 


\section{CESPUC \\ 2O SEMESTRE DE $2017-$ N. 31}

Chile (1999) afirma que esse é um dos problemas que a legendagem enfrenta, já que não é possível reter o estilo ou registrar as marcas do texto original, nem mesmo os componentes interpessoais de comunicação, o que pode acabar afetando o efeito do humor produzido originalmente.

É diferente com os livros, por exemplo, em que, caso o tradutor não esteja seguro de que vai conseguir passar a mensagem, ele pode acrescentar notas de rodapé que expliquem melhor ou o leitor pode simplesmente pesquisar em outros lugares sobre o assunto; claro que o espectador também pode pausar o programa para tentar entender melhor a cena, mas como acontece tudo muito rapidamente, o espectador geralmente vai ignorar o que não entendeu e continuar assistindo. Numa sitcom ${ }^{12}$, as risadas de fundo podem apontar para ele que há algo engraçado ali, mesmo que a legenda não tenha conseguido passar a mensagem. No caso de The Office, nem sempre o espectador vai perceber que tem algo diferente / engraçado na cena, porque nem sempre são piadas que estão expostas, como vai ser abordado mais abaixo.

\section{Humor e The Office}

The Office é uma adaptação estadunidense de uma série britânica de mesmo nome. A série conta a vida de funcionários da filial da Dunder Mifflin em Scranton, Pensilvânia, uma empresa que vende papel. A série foi gravada no formato de documentário, um estilo conhecido como mockumentary (mock $=$ falso + documentary $=$ documentário).

Em seu artigo "Novas modalidades de sitcom e o fenômeno confessional", Ceretta (2014) conta um pouco sobre essas séries no começo dos anos 2000. As séries de comédia eram geralmente gravadas em frente a uma audiência para depois serem exibidas, além de usarem várias câmeras (formato multicam). Mudanças importantes ocorreram com Malcolm in the Middle (2000) e Scrubs (2001), séries que marcaram o fim da plateia e o uso de câmeras fixas, além do uso do cenário em $360^{\circ}$.

A adaptação do The Office britânico chegou aos Estados Unidos em 2005. Em um artigo na TIME, sobre seis coisas que fizeram a série ser importante, o crítico de TV James Poniewozik (2013) afirma que as entrevistas no estilo confessionário e as câmeras correndo para seguir a ação eram familiares para os americanos por causa dos reality shows e The Office ajudou a trazer esse formato para a ficção americana (e foi seguido depois por séries como Modern Family e Parks and Recreation).

The Office não conseguiu bons números de audiência na primeira temporada. Isso pode ser explicado por variados motivos (dentre eles, as comparações com o original britânico, por exemplo), mas em uma entrevista para o $A . V$. Club, Mike Schur, produtor executivo da série, explica que The Office é essencialmente uma série sobre personagens e então o humor acaba sendo resultado de personalidades mais do que sendo resultado de situações inusitadas. $\mathrm{Na}$ maioria das vezes, é uma combinação dos dois casos, mas conhecer as personagens permite que

12 Sitcom é a abreviação de Situation Comedy, que significa comédia de situação. É um termo geral que abrange séries de comédia com variados estilos técnicos, sendo mais conhecidos o multicam (várias câmeras e geralmente filmado em frente a uma audiência) e o single cam (filmado no estilo de filmes). 


\section{（ESPUC \\ 2O SEMESTRE DE $2017-$ N. 31}

a situação se torne mais inusitada / engraçada. Schur afirma, por exemplo, que

Até que você conheça quem são essas personagens, você não vai achá-los tão engraçados. Muitas vezes, as pessoas me dizem "eu voltei pra assistir os seis primeiros episódios e eles são muito mais engraçados do que eu me lembro." (...) Parte da diversão é conhecer quem são essas pessoas. As pessoas acham que as personagens ficaram mais engraçadas e eu acho que a resposta real é que você simplesmente passou a conhecê-las. (SCHUR, 2011. Tradução minha)..$^{13}$

Além disso, o formato de mocumentário era algo relativamente novo nos Estados Unidos. Arrested Development (2003) é filmada em um estilo semidocumentário, mas as personagens nunca interagem diretamente com a câmera, apesar de serem apresentadas por um narrador. Mike Schur explica que a maior vantagem do formato de mocumentário é ser uma ferramenta que mostra como as pessoas agem de maneiras diferentes publica e privadamente. No podcast ${ }^{14}$ Fresh Air, Greg Daniels (2006), responsável pela adaptação de The Office nos Estados Unidos, analisa também como o uso do formato permite situações cômicas, exatamente por causa dessas personagens.

É como um reality show ou um documentário em que eles levaram as câmeras para um escritório típico americano e esse está localizado em Scranton, na Pensilvânia. E eles vendem algo muito comum e meio chato, papel e suprimentos de escritório para outros escritórios. E o chefe dessa filial está muito empolgado porque as câmeras estão lá e ele quer explicar a vida dele e torná-la o mais interessante e profissional possível, mas ele não consegue evitar alguns erros ou situações constrangedoras, porque essa é sua personalidade (DANIELS, 2006. Tradução minha). ${ }^{15}$

As personagens são elemento importante de The Office, exatamente porque se trata de uma série que mostra o dia a dia de um escritório, algo comum na vida de milhares de pessoas ao redor do mundo, um tema muito simplista, se analisado apenas assim; foram as personalidades exageradas - praticamente caricatas - de pessoas com quem os telespectadores convivem diariamente as responsáveis por tornar a série um sucesso de audiência ${ }^{16}$ e crítica.

Michael Scott, o gerente da filial, é extremamente subqualificado para o seu cargo. É estabelecido na série que ele era, sim, um bom vendedor de papel, mas por alguma razão, foi promovido para um cargo de liderança. No primeiro episódio, que é praticamente uma cópia da versão britânica, Michael é apresentado como alguém muito egocêntrico, que não sabe a

13 Until you know who the characters are, you just won't find them that funny. Very often, people say to me, "I went back and watched those first six episodes, and they're a lot funnier than I remember." (...) Part of the joy is getting to know who the people are. People think the characters got funnier, and I think the real answer is that you just got to know them.

14 Podcast é a junção de POD (Personal On Demand = pessoal sob demanda) e Broadcast (transmissão de rádio e TV), ou seja, é uma transmissão de rádio/vídeo sobre conteúdo específico para que as pessoas escutem/vejam quando quiserem, depois de fazer o download.

15 It's like a reality show or a documentary where they took the cameras to a typical american office and this one is in Scranton, Pennsylvania and they sell something very typical and kinda boring, which is just copier paper and office supplies to other offices. And the boss of this particular branch is so excited that the cameras are there, and he wants to explain his life and make it look as interesting and professional as possible, but he can't help making certain mistakes and putting his foot on his mouth, because that's his personality.

16 The Office não conseguiu bons números inicialmente, mas a NBC deixou episódios disponíveis no iTunes e viu a série em primeiro lugar das mais baixadas. No intervalo entre a primeira e a segunda temporada, Steve Carell apareceu nos cinemas com "O Virgem de 40 anos", um grande sucesso de bilheteria, o que acabou atraindo mais audiência para a série. 


\section{CESPUC}

Nathalia（ristina de Freitas（ampos

hora de parar de falar e costuma fazer afirmações desconfortáveis de cunho racista e sexista, além de se achar muito mais inteligente do que parece. A presença de câmeras só piora esse lado de sua personalidade. Ao longo da série, entretanto, é possível ver uma tentativa de tornar a personagem mais simpática para os telespectadores e é possível perceber que Michael é extremamente carente de atenção, não teve uma infância muito fácil, é uma pessoa otimista que se importa genuinamente com seus empregados, na maioria das vezes para o desconforto dos mesmos.

Ainda no podcast Fresh Air, Daniels (2006) disse que, quando as audições para essa personagem começaram, ele achava muito difícil dar instruções para os atores, então ele gravou uma audição e o conselho que ele deu foi que essa era uma personagem que tinha na cabeça que um dia o documentário iria ser assistido por Jennifer Aniston e ele gostaria de impressioná-la.

Dwight Schrute é uma outra personagem importante na série. Um nerd convicto e fazendeiro, ele é uma personagem cheia de contradições, mas, ao mesmo tempo, muito complexa e interessante, especialmente em termos humorísticos. Ele é assistente do gerente regional, um título inventado por Michael, e não liga para o que as pessoas falam, exceto o chefe, que ele considera o melhor amigo. Isso faz com que Dwight acabe acobertando um pouco a falta de noção e muitas vezes ajudando seu chefe a pôr em prática as ideias sem pé nem cabeça.

Apesar de ser possível se identificar com uma ou outra coisa estranha que Michael e Dwight falam, é em Jim e Pam, que completam o quadro de personagens principais, que o público pode se enxergar melhor. Jim é um vendedor que está estagnado no emprego e Pam é a secretária, que também trabalha na Dunder Mifflin porque não tem mais perspectivas de vida, apesar de ser uma artista talentosa. Jim, especialmente, tem um relacionamento familiar com a câmera e é possível vê-lo reagindo diretamente com o público quando Michael fala ou faz algo que ultrapassa os limites do bom senso. É um dos momentos que é possível demarcar que a situação foi engraçada, mesmo sem que a legenda esteja apropriada. Suas reações variam de "não é possível" e "você tá vendo o que eu estou vendo?", através de suas reações faciais, mas também nas vezes que ele conversa diretamente com a câmera.

O elenco secundário é parte importante das tentativas falhas de Michael para tentar se enturmar com sua equipe e eles constantemente mostram seu desconforto com o chefe para a câmera e também falando com a equipe do documentário.

Ben Collins, um editor do Hulu, em um artigo do Huffington Post chamado Is The Office the Definitive TV Show of the '00s?, afirma que os estadunidenses estavam bem familiarizados com as personagens da série, porque elas refletiam o país muito bem em um tempo tão estressante, um período de recessão nos Estados Unidos, quando as pessoas iam atrás dos seus sonhos e falhavam sempre. Essas personagens "acidentalmente acabaram definindo o ideal americano por alguns anos." (COLLINS, 2013. Tradução minha). ${ }^{17}$

Outro aspecto importante apontado por Poniewozik (2013), que fez de The Office uma série importante, foi o fato de trazer de volta o drama para as comédias; ele ressalta que não era

17 "accidentally defined the American ideal for a few years." 


\section{C $\stackrel{\text { aderns }}{E}$ PUC \\ $2^{\circ}$ SEMESTRE DE $2017-$ N. 31}

exatamente uma série política, mas tratava as personagens com seriedade quando necessário. Ainda de acordo com o crítico, a série ajudou a divulgar características de comédias populares na TV a cabo, como as cenas superconstrangedoras; mostrou que comédias não precisam ser simplistas para serem entendidas (o público consegue acompanhar uma storyline, mesmo que ela não termine em um episódio) e, algo muito importante: mostrou situações realistas de trabalhadores americanos, como problemas com demissões e treinamentos sobre assuntos sensíveis.

\section{Analisando The Office e revisndo o humor das legendas}

The Office apresenta piadas de todos os tipos propostos por Zabalbeascoa (1996) e também cenas que mostram teorias de incongruência e superioridade, mas, para este estudo específico, o foco será apenas nas piadas da série que dependem da língua, quinto aspecto apresentado por Zabalbeascoa (1996). De acordo com o autor, as piadas que dependem da língua necessitam de algumas características naturais da língua para que façam efeito, por exemplo o uso de polissemia, homofonia ou zeugma.

Delia Chiaro (1992), em seu estudo "The Language of Jokes: Analysing Verbal Play", apresenta alguns outros aspectos de piadas que dependem da língua, como malapropismos, metátese, além do uso de palavras equivocadas. Ela classifica esses recursos como deslizes da língua que acabam se tornando parte de piadas.

Para Zabalbeascoa (1996), "piadas desse tipo podem acabar sendo consideradas 'internacionais', já que podem acabar sendo traduzidas mais ou menos literalmente quando duas línguas são muito próximas.” (ZABALBEASCOA, 1996, p. 253. Tradução minha). ${ }^{18}$

O foco específico dessa análise será o ponto de vista de Michael Scott, o protagonista da série. Como ele conversa muito com a câmera, nem sempre o humor da situação é facilmente notado pelo telespectador, especialmente considerando-se a pronúncia errada, usando palavras que tem sons similares, como veremos abaixo. Nesses casos, o trabalho do tradutor e, posteriormente, do revisor é fundamental para que o humor continue na situação e se ajuste ao contexto audiovisual.

Uma das piadas recorrentes de The Office são as botched phrases, numa tradução livre, as frases arruinadas por Michael, que, como já foi estabelecido, é alguém que quer impressionar as câmeras e seus subordinados; quando ele começa a falar, no entanto, acaba se confundindo e estragando ditos populares e expressões comuns, além de usar a pronúncia errada de algumas palavras, na tentativa de parecer mais sábio e inteligente. Essas cenas também mostram como a teoria da superioridade e da incongruência podem gerar humor: quando Michael está falando algo que não tem sentido em público (incongruência), não só o telespectador ri da falta de noção, mas é encorajado a fazê-lo pelas reações que seus funcionários mostram na câmera (superioridade). Quando ele fala ou tenta explicar suas ações absurdas (incongruência) apenas para a câmera, o telespectador também ri, porque ele não faz muito sentido (superioridade).

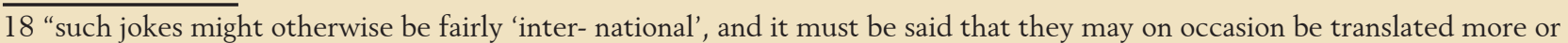
less literally when the two languages are very closely related." 


\section{CESPUC \\ 20 SEMESTRE DE $2017-$ N. 31}

Nesse último caso, é ainda mais evidente a importância de uma tradução e uma revisão bem feitas, porque não há nenhum outro indicativo na cena de que ele está pronunciando palavras erradas ou mudando expressões famosas. Foi possível notar que, nas cenas selecionadas, algumas traduções ignoram que o que Michael fala está errado, do ponto de vista da pronúncia, o que faz com que a cena perca totalmente o humor desejado. Um conhecimento prévio sobre a personagem e sobre o tipo de humor da série poderia ajudar para que as cenas transmitissem de maneira mais eficiente a mensagem original da cena.

Abaixo foram selecionadas 15 cenas diferentes e foram feitas análises sobre o contexto do material, como foi feita a tradução e como o trabalho de um revisor poderia ter ajudado a melhorar o humor da cena para falantes de português. Foram levados em consideração os aspectos apresentados por Chile (1999) e Chiaro (2006) sobre a efemeridade da legenda, como os tradutores tem um espaço limitado para passar a mensagem da cena e como ela é apenas mais uma parte de toda a construção audiovisual da cena.

\section{$1 \times 01-$ Pilot}

O pilot de The Office é essencial para estabelecer o relacionamento de Michael Scott com a câmera e para que a audiência entenda que essa é uma personagem que está sempre tentando aparecer demais. A base de toda a série são os funcionários de Michael reagindo às coisas inapropriadas que ele fala e faz, seja quando está tentando impressionar a câmera ou quando está tentando fazer com que eles sejam seus amigos. Por causa disso, o uso de palavras complicadas é parte essencial do seu vocabulário e a maneira como ele as pronuncia de forma errada é uma parte importante da essência dessa personagem.

Nessa cena, ele está se apresentando para a câmera, conversando sobre quais são seus grandes heróis e ele cita pessoas como Bob Hope, Abraham Lincoln, Bono e Deus, que ele menciona que provavelmente estaria em quarto lugar. Depois ele diz: And I just think all those people really helped the world in so many ways that it's, um... it's really beyond words. It's really uncalculable. É possível perceber que ele está tendo dificuldades para encontrar a palavra correta, então ele acaba falando algo que não existe. A tradução do DVD brasileiro, no entanto, ignora esse erro. Essa cena é traduzida assim: Esses caras realmente ajudaram o mundo de tantas formas... que não dá pra descrever. É realmente incalculável. Para consertar a tradução de maneira simples, nesse caso, era só mudar a palavra incalculável para uma outra que não existe, mas que faça o telespectador identificar o que a personagem está tentando falar - e rir - como por exemplo, descalculável, colocado entre aspas para mostrar o erro evidente.

\section{$2 \times 22$ - Casino Night}

Michael está organizando uma noite do cassino na filial de Scranton e durante seu monólogo com a câmera, ele afirma que sabe que é algo ilegal na Pensilvânia, mas it's for charity. And I consider myself a great philanderer. O problema é que ele não fala philanthropist, mas philanderer, palavra que indica alguém (geralmente um homem) namorador, galanteador, 
alguém que tem muitos casos. Novamente a tradução desconsidera totalmente o jogo de palavras e diz apenas: É pra caridade. E eu me considero um grande filantropo.

Lembrando o estudo de Chiaro (1992), podemos ver que o acontece nessa cena é um malapropismo, um deslize da língua que ficou muito conhecido por causa de Mrs. Malaprop, na peça Os Rivais, de 1775. A personagem é famosa por usar palavras que não fazem sentido na frase ao invés das que seriam corretas, por causa do som similar. Philanthropist e philanderer não têm tantas semelhanças sonoras, mas como Michael continua falando que se sente bem sabendo que, por causa dele, uma criança no Congo vai dormir com a barriga cheia de arroz, é óbvio que ele está falando sobre se considerar um philanthropist. O uso de philanderer nessa frase é porque ele está tentando se exibir (ou porque não sabe a palavra correta), mas nesse mesmo episódio, Michael acaba marcando um encontro com duas mulheres e tem que manter as duas distraídas durante seu evento, então philanderer acaba sendo um presságio do restante da sua noite.

Uma tradução adequada à piada correta é complicada nessa situação porque não existe uma palavra com sonoridade similar que se encaixe no significado de philanderer, porém é possível modificar um pouco a piada de acordo com a tradução. São duas sugestões diferentes nesse caso:

- Na primeira, para mostrar que ele está falando filantropo de maneira errada, a sugestão de tradução seria apenas de mudar a palavra para outra, escrita de maneira errada, realçada com aspas, algo como "E eu me considero um grande filitropolista." Nesse caso, porém, a piada perde o duplo sentido e o malapropismo.

- A segunda sugestão é um pouco mais elaborada, mas pode funcionar. Se na legenda estiver algo como "E eu me considero um grande filistino", o malapropismo não funciona tão bem, mas ainda assim é uma palavra que existe em português (como philanderer), tem sons semelhantes ao do conjunto philanderer $\mathrm{x}$ philanthropist e se o telespectador tiver conhecimento prévio sobre filistinos, ele vai saber que Michael acabou de referir a si mesmo como alguém que é considerado inculto e desprovido de inteligência, de acordo com o dicionário Houaiss, mas também é uma palavra que apresenta contexto bíblico (filistino = filisteu). É recomendado que esteja entre aspas, pois mesmo sendo uma palavra que existe, as aspas indicam para o telespectador que ela está sendo usada da maneira errada.

\section{$3 \times 2$ - The Convention}

Nessa cena, Michael reencontra Jim pela primeira vez desde que este pediu transferência da filial de Scranton. Ele quer falar the prodigal son returns, mas se confunde e acaba falando The... Progidal... my son returns. Como progidal não significa nada em inglês, a tradução $\mathrm{O}$ prodígio, o filho pródigo... O retorno do meu filho, apresenta dois problemas: 1) o uso de prodígio, quando deveria ser usada uma palavra inventada e 2) o uso de 'o filho pródigo' logo depois, como uma tentativa de explicar a piada para o telespectador, de mostrar o que Michael 
quis dizer ao invés do que ele acabou dizendo. É uma fala que não existe na série, porque ele gagueja, fala progidal, gagueja mais um pouco e termina com my son returns. É visualmente perceptível que ele não sabe o que está falando, então aumentar a frase e colocar a palavra certa descaracteriza a piada. Uma sugestão que funcionaria melhor para manter o sentido do que acontece na cena seria colocar uma palavra inventada, assim como prodigal, entre aspas para mostrar que está mesmo errada e traduzir o restante literalmente, como: O... 'prógido' ... meu filho retorna.

Nesse mesmo episódio, Michael está conversando com Dwight sobre o gerente da filial de Stanford, onde Jim está trabalhando. Ele não aceita que Josh, o gerente, seja assim tão perfeito e quer descobrir eventuais problemas que possam ajudá-lo a desmascarar o concorrente. Ele, então, pede a Dwight: I want you to dig up some dirty on Josh, find out if there are any skeletons in his attic. Como já foi dito, Dwight é um faz tudo pra Michael, então ele nem pisca para considerar que a expressão está errada e sai para fazer o que Michael pediu. A tradução usada no Brasil foi: Preciso que procure algum podre do Josh. Veja se ele tem segredos escondidos. A piada está totalmente perdida e o telespectador não tem nenhum referencial de que Michael acabou de errar, porque Dwight não tem nenhuma reação, uma característica particular dessa personagem.

A expressão correta, em inglês, é skeletons in the closet, mas Michael fala in his attic. A tradução usada no Brasil é esqueletos do armário e foi incorporada com o passar do tempo por aqui, com a tradução literal. É possível ver esse uso, por exemplo, em reportagens que mencionam escândalos políticos, já que significa falar sobre um segredo obscuro ou muito bem guardado. Michael menciona attic, que é último andar de uma casa, o espaço aproveitado sob o telhado. No Brasil, não é comum que áticos sejam utilizados, então a expressão errada de Michael "no seu ático", também ficaria estranha aqui. A sugestão nesse caso seria usar "Veja se ele guarda esqueletos no seu porão" ou algum lugar menos convencional que um porão (que já é um lugar associado com entulho e bagunça), para que o telespectador possa perceber o erro, como por exemplo "Veja se ele guarda esqueletos na sua despensa. "

Ainda nesse episódio, temos um caso especial. Michael está conversando com a câmera sobre o seu relacionamento com Jim, sobre como os dois continuam amigos, mesmo não trabalhando mais no mesmo lugar (não é exatamente verdade, mas como Jim conversou com Michael sobre seus sentimentos por Pam, ele acredita que os dois são melhores amigos) e então ele diz: Because a real relationship, it can't be forced. It should just come about effortledlessly. Essa cena está legendada em inglês como effortlessly, no entanto a fala do Michael é effortledlessly. Como é mais um momento que ele está falando com a câmera, é fácil perceber que ele está tentando fazer a palavra soar mais difícil do que realmente é, mas isso se perde porque a tradução ficou sendo: Uma relação de verdade não pode ser forçada. Tem que vir sem esforço. Não dá pra culpar o tradutor, até porque é difícil saber se ele teve acesso ao material audiovisual, mas a sugestão de tradução seria usar uma palavra inventada, com aspas para dar ênfase, como por exemplo: Uma relação de verdade não pode ser forçada. Tem que vir 'desesforçadamente. 


\section{Chane

\section{$3 \times 14-$ Ben Franklin}

Essa também é uma cena que Michael está conversando com a equipe do documentário, dessa vez sobre uma ideia que ele teve: gravar uma mensagem para um provável filho que ele (provavelmente) vai ter no futuro. Ele diz: Yesterday, I was scraping some gunk off my wall sockets with a metal fork and I gave myself the nastiest shock. And when I came to, I had an epiphery. Life is precious. And if I die, I want my son to know the dealio. The dealio of life. Ele menciona que teve uma epiphery, que é uma palavra que não existe, mas ele quer dizer epifania. A tradução ignora a piada completamente: Ontem eu estava arrancando um chiclete preso na tomada com um garfo... e eu levei um terrível choque. Quando acordei, cheguei a uma conclusão. A vida é preciosa. E se eu morrer, eu quero que meu filho... conheça os fatos. Os fatos da vida. Como ele está conversando com a câmera, é difícil que o telespectador perceba o humor se a tradução não estiver correta, então a sugestão é que a tradução use uma palavra inventada, destacada por aspas, como 'epiferia', por exemplo.

No momento seguinte, Michael menciona que quer que o filho saiba o dealio da vida. Dealio é uma gíria adaptada de deal, geralmente usada para fazer a pessoa parecer mais descolada, como nessa situação. Nesse caso, a tradução tem que seguir o estilo e colocar uma gíria também. É importante pensar que gírias têm uma vida útil muito curta, mas nesse caso, não tem problema se for uma gíria antiga ou em desuso, já que condiz com as características da personagem falar coisas que soam legais para ele, mas não são para mais ninguém. A cena inteira, numa sugestão de tradução melhorada seria: Ontem eu estava arrancando um chiclete preso na tomada com um garfo... e eu levei um terrível choque. Quando acordei, cheguei a uma 'epiferia'. A vida é preciosa. E se eu morrer, eu quero que meu filho... conheça 'as paradas'. 'As paradas' da vida.

\section{$3 \times 20$ - Product Recall}

Michael está fazendo um vídeo para o futuro, para que fique registrado que ele não é o culpado por um problema com as resmas de papel. Ele tenta falar scapegoat, mas acaba falando escape goat: They're trying to make me an escape goat. Como a pronúncia é muito parecida, o tradutor pode acabar se confundindo e achar que ele está mesmo falando scapegoat. A tradução ficou assim: Estão tentando me fazer de bode expiatório e tecnicamente está correto, mas como a legenda em inglês apresenta a versão com escape goat, a sugestão seria fazer a tradução mudando a expressão bode expiatório, que também é conhecida e usada no Brasil: "Estão tentando me tornar uma cabra expiatória."

\section{$3 \times 21$ - Women's Appreciation}

Nessa cena Michael está citando a música de Aretha Franklin, Respect, mas ele erra ao soletrar: Respect. R-E-S-P-C-T. Find out what it means to me. A tradução não segue a legenda original: R-E-S-P-E-I-T-O. Descubra o que isso significa pra mim! Uma sugestão simples é 


\section{C aderns \\ 2O SEMESTRE DE $2017-$ N. 31}

apenas tirar uma letra e colocar entre aspas, pra mostrar que está errado de propósito, como por exemplo: “'R-E-S-P-E-T-O.' Descubra o que isso significa pra mim?” É possível que o público não vá perceber a falta de uma letra por causa da velocidade da legenda, mas é algo simples de ser corrigido, prezando pela qualidade do produto.

Nesse mesmo episódio, Michael está falando com a câmera e faz uso do sufixo unantes de understandable porque ele está tentando negativar o understandable (que significa compreensível) e fazer um paralelo com o understands que ele usou segundos antes: Any man who says he totally understands women is a fool. Because they are un-understandable. A tradução da legenda foi feita como incompreensíveis mas, apesar de passar o sentido correto do que Michael estava tentando dizer, ela perde a piada: Qualquer homem que diz que entende as mulheres é um tolo. Porque elas são incompreensíveis. A sugestão seria colocar uma palavra como "uneincompreensíveis" entre aspas, para mostrar que é um erro consciente, porque, apesar de não estar literalmente parecida com a original, dá para entender o que ele está tentando falar e mantém que ele está falando da maneira errada: Qualquer homem que diz que entende as mulheres é um tolo. Porque elas são 'uneincompreensiveis.'

\section{4 x 09 - Dinner Party}

Depois de muitas tentativas, Michael conseguiu fazer com que Jim e Pam fossem jantar em sua casa para um encontro duplo de casais. Ele está namorando Jan e quer impressionar seus convidados com seu conhecimento sobre vinhos, mas ele acaba confundindo aftertaste, o gosto residual do vinho na boca, com afterbirth, também chamado de placenta: That's sort of an oaky afterbirth. É possível notar que ele fala uma coisa errada por causa da reação dos outros presentes na sala, especialmente Jim, mas ainda que a tradução esteja tecnicamente correta (Tem gosto de placenta), ela deixa de ser engraçada porque ele não falaria que um vinho tem gosto de placenta de propósito, ele está tentando ser chique e começa da maneira correta, mencionando o amadeirado, mas erra depois. Uma sugestão de tradução que mantém a piada de forma semelhante ao jeito que foi escrita seria algo como "Tem um gostinho 'aplacentado.", porque faz referência ao amadeirado que não cabe na frase, dá para entender que ele está falando coisa errada por causa das aspas e fica mais parecida com a ideia original.

\section{$5 \times 6$ - Customer Survey}

Nessa cena Michael está lendo uma resenha que um cliente deixou para Jim e provavelmente está escrito errado no papel, mas ele acaba insistindo no erro:

Michael: "Jim Halpert is smudge and arrogant."

Jim: I think he means smug.

Michael: Arrogance.

Jim: Michael, I'm just trying to... 


\section{CESPUC \\ 20 SEMESTRE DE $2017-$ N. 31}

Michael: And there's our smudgeness.

Smudge é uma palavra que existe e significa manchado, mas dificilmente faria sentido para se referir a uma pessoa. A tradução brasileira é:

Michael: "Jim Halpert é 'mitido' e arrogante."

Jim: Acho que ele quis dizer "metido".

Michael: Arrogância.

Jim: Michael, estou só tentando...

Michael: E agora está sendo metido.

Obviamente é mais complicado fazer um jogo de palavras na tradução, mas não faz sentido traduzir como 'mitido', até porque 'mitido' e 'metido' tem basicamente a mesma pronúncia, mas smudgeness não é uma palavra que existe, então uma sugestão mais fácil seria inventar uma palavra para a tradução de smudge e uma outra para smudgeness, já que só assim seria possível manter a piada da cena. É importante simbolizar as palavras erradas com aspas, então a sugestão para a tradução seria algo como:

Michael: “Jim Halpert é 'convenecido' e arrogante.”

Jim: Acho que ele quis dizer "convencido".

Michael: Arrogância.

Jim: Michael, estou só tentando...

Michael: E ai está a 'convenecidência.'

\section{5 x 17 - The Golden Ticket}

Nessa cena, Michael está conversando com seus empregados na sala de reunião. Ele colocou cinco papéis dourados em caixas de papel e cada uma delas oferece um desconto de $50 \%$ na próxima compra do cliente. Ele considera essa a melhor ideia que ele já teve e também acha que os seus funcionários devem apresentar melhores ideias para movimentar o negócio: It is my responsibility as manager of this branch to profiligate great ideas. A tradução ignora o uso de propagate de maneira errada e muda a ideia da frase também, já que ele quer falar sobre espalhar boas ideias, porque considera que já apresentou sua boa ideia: É minha responsabilidade... enquanto gerente dessa filial, apresentar boas ideias. É outro momento que Michael está tentando parecer mais inteligente do que é, então uma sugestão simples a ser usada na tradução é simplesmente colocar aspas para marcar uma palavra inventada: É minha responsabilidade... enquanto gerente dessa filial, 'propaligar' boas ideias. 


\section{$5 \times 18$ - The New Boss}

Nessa cena, Michael está tentando entrar em contato com o seu superior, David. Já que ele não pode atender ao telefone, Michael deixa um recado: Well, just tell him to call me ASAP as possible. ASAP é uma sigla que significa As Soon As Possible, geralmente usada para mensagens de texto e internet. É mais um exemplo de Michael tentando parecer mais descolado do que ele é. A tradução brasileira é: Bem, diga pra ele me ligar A.Q.P. quando puder, que apesar de estar literalmente correta, falha no quesito humor para o espectador brasileiro, porque não usamos a sigla A.Q.P. para falar "assim que puder" ou "assim quando puder." Uma maneira de corrigir seria usar "diga a ele pra me ligar possivelmente o mais rápido possível" ou "o mais rapidamente rápido possível". Nenhuma das duas opções de tradução consegue trazer o humor da fala original, já que ela envolve Michael Scott usando uma sigla errada, mas as duas sugestões deixam o contexto da frase mais claro para o espectador.

Nesse mesmo episódio, Michael está confrontando as decisões tomadas pelo novo contratado da empresa, que está lá para vigiar o seu serviço e arrumar alguns problemas que a filial de Scranton está tendo. Quando Charles pede almoço para todo mundo, Michael questiona por que ele está gastando com comida, se está na empresa para cortar despesas. Ele diz: I think it's a little hypercritical. A tradução ignora completamente o uso errado da palavra e traduz simplesmente como: Acho que é um pouco hipócrita. Novamente, a solução para uma tradução que melhor atenda ao humor da cena é inventar uma palavra e colocar ela entre aspas para acentuar o erro: Acho que é um pouco 'hipercrita.'

\section{$5 \times 23-$ Broke}

Pela primeira vez em muito tempo, Michael fez algo que ameaça os negócios da Dunder Mifflin: ele pediu demissão de seu emprego e abriu uma nova empresa, a Michael Scott Paper Company, que vende os mesmos produtos, mas por preços irrisórios. Os gerentes superiores ficam preocupados com o que isso pode significar em longo prazo para a Dunder Mifflin e pedem uma reunião com Michael, que, querendo mostrar como a situação mudou diz Well, well, well, how the turntables... para os seus antigos chefes. A tradução em português ficou sendo Ora, ora, ora... Como o mundo gira..., que está tecnicamente correta e passa a ideia original do texto, mas perde o efeito cômico, já que o que Michael quer dizer é na verdade How the tables have turned. Essa é uma expressão que significa "reverter uma posição em relação a outra pessoa", de acordo com o Oxford Dictionary e é muito usada em esportes, por exemplo. No Brasil, uma frase com significado similar seria "parece que o jogo virou" ou também "a maré mudou", já que conseguem passar essa ideia de reversão. Como Michael não diz a expressão original da maneira certa, uma sugestão seria usar "Ora, ora, ora... parece que 'a virada jogou'”, entre aspas, pra mostrar que o erro é proposital. 


\section{Considerações finais}

A partir da amostra escolhida, é possível concluir que a tradução feita nas cenas selecionadas não foi satisfatória. Tanto a tradução quanto a revisão (ou a falta da mesma) deixam a desejar nas tentativas de transmitir o humor da cena. De acordo com a teoria de Zabalbeascoa (1996), as piadas que foram escolhidas para análise nesse artigo são as que dependem do entendimento da língua, o que torna a tradução um pouco mais complicada, já que "muitas vezes substituições radicais ou outras grandes mudanças são necessárias, dependendo das prioridades" (ZABALBEASCOA, 1996, p. 253. Tradução minha). ${ }^{19}$

No caso de The Office, o humor com os erros de linguagem é uma característica importante da personagem e sem a tradução bem feita, o humor da cena pode ser completamente perdido, como aconteceu em alguns casos analisados.

Apesar de ser efêmera, uma tradução que seja a mais fiel possível é necessária para que o telespectador possa compreender bem os diferentes contextos verbais e não verbais que acontecem ao mesmo tempo em uma cena, já que apesar de ter muitas cenas com dicas visuais de piadas, uma grande parte delas depende principalmente que o telespectador entenda o diálogo da personagem com a câmera, mesmo por questões de continuação, para que ele compreenda o restante do episódio e das situações.

É desafiador para o tradutor e para o revisor manter não só o humor da série de forma fidedigna nas legendas, mas se adequar aos padrões de tempo e espaço que elas demandam, sempre levando em consideração que o humor vai ser resultante de um contexto que não analisa a legenda sozinha.

É necessário que tanto tradutor quanto revisor tenham um pouco de liberdade criativa para que o texto original (e a sua função de fazer o telespectador rir) não se perca completamente. $\mathrm{O}$ ideal seria um conhecimento prévio sobre a série e suas particularidades, para ser um trabalho que assimilasse mais o humor presente na língua fonte. É possível perceber também que esse é um tema que pode ser expandido em variados estudos, como por exemplo, análises de cenas que demandam atenção visual ou que apresentam referências de cultura popular nos Estados Unidos.

\section{Referências}

BAKER, Mona. In other words: A coursebook on translation. $2^{\text {nd }}$ edition. New York: Routledge, 2011. Edição do Kindle.

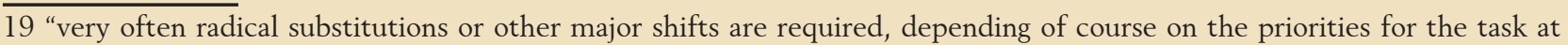
hand." 


\section{Aderns \\ 2O SEMESTRE DE $2017-$ N. 31}

CARVAlHO, Carolina Alfaro de; FROTA, Maria Paula. A tradução para legendas: dos polissistemas à singularidade do tradutor. 160 f. 2005. Tese de Doutorado. Dissertação (Mestrado em Letras) - Departamento de Letras da Universidade Católica do Rio de Janeiro, Rio de Janeiro. Disponível em: <http://www.scribatraducoes.com.br/files/ CarolinaAlfaroCarvalho_2005_TraducaoParaLegendas_Dissertacao.pdf $>$. Acesso em: 04 fev. 2017.

CERETTA, Fernanda Manzo. Novas modalidades de sitcom e o fenômeno confessional. Sessões do Imaginário, v. 19, n. 31, p. 51-58, 2014. Disponível em: < http://congreso.pucp. edu.pe/alaic2014/wp-content/uploads/2014/10/GI3-Fernanda-Ceretta.pdf $>$. Acesso em: 05 jan. 2017.

CHIARO, Delia. Verbally expressed humour on screen: Reflections on translation and reception. The Journal of Specialised Translation, v. 6, p. 198-208, 2006. Disponível em: $<$ http://citeseerx.ist.psu.edu/viewdoc/download?doi $=10.1 .1 .582 .140 \&$ rep $=$ rep $1 \&$ type $=p$ df>. Acesso em: 21 dez. 2016.

CHIARO, Delia. The language of jokes: Analysing verbal play. New York: Routledge, 1992. Edição do Kindle.

CHILE, Daniela M. Ioppi. The Sitcom Revisited: The Translation of Humor in a Polysemiotic Text. Cadernos de Tradução, v. 1, n. 4, p. 167-204, 1999. Disponível em: < https://periodicos. ufsc.br/index.php/traducao/article/viewFile/5531/4990+http:/griffon:nnnnnnn@>. Acesso em: 05 jan. 2017.

COLLINS, Ben. Is The Office the Definitive TV Show of the '00s?. Huffington Post. 16/5/2013. Disponível em: <http://www.huffingtonpost.com/hulucom/the-office-finale_b_3285484. html>. Acesso em: 07 jan. 2017.

DANIELS, Greg. Fresh Air: Writing The Office with Greg Daniels and Mindy Kaling. In: GROSS, Terry. 2/11/2006. Disponível em: <http://www.npr.org/templates/story/story. php?storyId=6422523 > . Acesso em: 05 jan. 2017.

MUNIZ JR., José de Souza. A intervenção textual como atividade discursiva: considerações sobre o laço social da linguagem no trabalho de edição, preparação e revisão de textos. In: XXXII Congresso Brasileiro de Ciências da Comunicação, 2009, Curitiba. Anais... Curitiba: Intercom. Sociedade Brasileira de Estudos Interdisciplinares da Comunicação, 2009. Disponível em: <http://www.intercom.org.br/papers/nacionais/2009/resumos/R4-1079-1.pdf>. Acesso em: 04 fev. 2017.

PONIEWOZIK, James. Six Ways The Office Mattered. TIME, Tuned In. 16/5/2013. Disponível em: <http://entertainment.time.com/2013/05/16/six-ways-the-office-mattered/>. Acesso em: 05 jan. 2017.

POSSENTI, Sírio. Humor, língua e discurso. 1. ed. $2^{\text {a }}$ reimpressão. São Paulo: Contexto, 2014. Edição do Kindle. 
SANTOS, Clarissa Soares dos. A revisão como atividade interventora no processo tradutório. 2007. Tese de Doutorado. PUC-Rio. Disponível em: < http://www.lambda.maxwell.ele.pucrio.br/10739/10739_1.PDF>. Acesso em: 04 fev. 2017.

SCHUR, Michael In: HEISLER, Steve. Interview: Michael Schur. AVClub. 24/3/2011. Disponível em: <http://www.avclub.com/article/michael-schur-53574>. Acesso em: 07 jan. 2017.

VANDAELE, Jeroen. Each time we laugh: Translated humour in screen comedy. In: Translation and the (re) location of meaning. Selected papers of the CETRA research seminars in translation studies. p. 237-272. 1999. Disponível em: < http://www.arts.kuleuven.be/cetra/papers/files/ vandaele-1999.pdf>. Acesso em: 15 dez. 2016.

VANDAELE, Jeroen. Humor in translation. Handbook of translation studies, v. 1, p. 147152, 2010. Disponível em: <http://folk.uio.no/jeroenv/Vandaele\%20Humor\%20in\%20 Translation_proofs.pdf $>$. Acesso em: 15 dez. 2016.

ZABALBEASCOA, Patrick. Translating jokes for dubbed television situation comedies. The translator, v. 2, n. 2, p. 235-257, 1996. Disponível em: < https://www.academia.edu/3331256/ Translating_Jokes_for_Dubbed_Television_Comedy >. Acesso em: 15 dez. 2016.

ZABALBEASCOA, Patrick. Humor and translation - an interdiscipline. p.185-207, 2005. Disponível em: <http://m.repositori.upf.edu/bitstream/handle/10230/22492/zabalbeascoa humor_2005.pdf?sequence=1 >. Acesso em: 21 dez. 2016.

\section{THE OFFICE}

Direção: Charlie Grandy, Steve Hely, Steve Burgess, Randall Einhorn, Matt Sohn, Sarah Levy, Peter Smokler. Produção e Roteiro: Greg Daniels, Ricky Gervais, Stephen Merchant, Howard Klein, Ben Silverman, Paul Lieberstein, Jennifer Celotta, B. J. Novak, Mindy Kaling, Brent Forrester e Dan Sterling. Intérpretes: Steve Carell, Rainn Wilson, John Krasinski, Jenna Fischer, B. J. Novak, Ed Helms, Melora Hardin, David Denman, Leslie David Baker, Brian Baumgartner, Kate Flannery, Angela Kinsey, Oscar Nuñez, Phyllis Smith, Mindy Kaling, Paul Lieberstein, Creed Bratton, Amy Ryan, Craig Robinson, Ellie Kemper e Zach Woods. Universal Studios 2005-2013. Produzido e distribuído por AMZ Mídia Industrial S.A. The Office - A coleção completa. 34 discos. Duração aproximada: 4493 min. 2005-2013. son. 5.1 DD, color., Widescreen Anamórfico. 